\title{
Light Pollution: How High-Performance Luminaires Can Reduce It
}

Christian Remande ${ }^{1}$, Chairman of the "Exterior Lighting" Committee of the "Syndicat de l'Eclairage Franais" and the members of the Lighting Applications Department, R-Tech Company

R-Tech, Rue de Mons, 3 - 4000 Liège, Belgium

\begin{abstract}
In 1984 the International Commission on Lighting (CIE) set up a Technical Committee TC 4.21 to study interference by artificial light in astronomical observation. The resulting document "Guidelines for minimizing sky glow" (CIE No. 126) complements previous CIE documents from 1978 and the joint CIE-IAU (International Astronomical Union) publication of 1984. In this paper, we demonstrate how high performance luminaires based on more global and pertinent criteria can significantly reduce sky glow.
\end{abstract}

\section{Introduction}

A detailed analysis of the phenomenon 'sky glow' produced by street lighting luminaires clearly shows that not only the direct but also the indirect (or reflected) contribution has a strong impact on the total upward-emitted light. Street lighting design calculations were made for several typical light distributions, several types of light sources, the families of road reflection surfaces (R1 to R4), and also for various types of installations (single- and double-sided). Taking into account the variation of all these parameters made it possible to calculate several criteria among which are:

- the 'classical' Upward Waste Light Ratio (CIE criterion)

- the total needed flux for a 'one $\mathrm{km}$ installation' to reach a given common value of luminance (reference level)

- the total direct emitted flux from the installation

- the total reflected flux from the installation (road plus surroundings)

These calculations clearly show that the reflected contribution of light can reach 5 to 8 times larger values than the direct upward-emitted light. If, for the same luminance level, a given installation can lead to much lower values of installed $\mathrm{lm} / \mathrm{km}$ (sum of the flux of all the light sources), then the global (direct plus reflected) portion of light that will be upward-emitted can also be largely

${ }^{1}$ This paper was presented by Marc Gillet. 
reduced. This can be achieved by high-performance optical systems. This approach enabled us to show clearly that the existing CIE criteria are much too restrictive and that there is an urgent need to take into account more global criteria incorporating not only the direct but also the reflected portion of light.

\section{Artificial Lighting}

More and more human activity is carried out during the hours of darkness, either as an extension of daylight activities (public works, police, transport, maintenance, etc.), or activities of a specifically nocturnal nature (parties, walks, theatre performances, sporting events, security patrols). This is only possible thanks to the existence of artificial light, which is an essential part of our lives. It is important to evaluate the environmental impact of this proliferation of exterior lighting in order to keep in check certain harmful effects which might exceed permissible limits (unwarranted intrusion into homes, glare, interference with observation of the night sky). The happy medium is yet to be found.

It is particularly in the urban environment that we encounter all the existing forms of lighting:

- functional and decorative public lighting for roads and security

- ambient lighting for pedestrian areas, footpaths, residential areas

- floodlighting of buildings

- floodlighting with high masts, road and rail complexes and some car parks

This is because amazing progress has been made in lighting techniques in the last forty years: efficiency of lighting equipment has doubled, expected life of light sources has doubled then quadrupled, and there is an immense range of lights of all levels of power, allowing a wide choice for aesthetic effects in surroundings where colour temperature and requirements for exact reproduction of the desired colours are of prime importance. The photometric outputs of the lights have been adapted for multiple uses, including decorative, functional, sporting and road lighting.

Artificial lighting has become an indispensable tool for improving the appearance of towns and an essential element in the quality of life of the inhabitants; it lights up the achievements of all the other technologies but, as in all technical progress, success engenders abuses and errors and attracts unqualified people who only seek financial gain. For about fifteen years, certain groups have been worried about the proliferation of exterior lighting and have felt acute concern about the increasing pollution of the night sky, which interferes with astronomical observation.

In the same way, certain lighting installations which are unsuited to the environment where they are sited cause problems at night by:

- extension of their light beyond the area it is intended to illuminate

- producing glare which is noticeable to residents

- casting light on facades and interior of private houses 
Lighting professionals must pay attention to these grievances, even if they are questionable.

Recommendations aimed at limiting the various types of light pollution have already been put forward in several countries of the European Union, e.g. the United Kingdom and Italy.

In 1984 the International Commission on Lighting (CIE) set up within Division 4 a technical committee TC 4.21 , to study interference by artificial light in astronomical observation. The resulting document "Guidelines for minimizing sky glow" (CIE No. 126) complements previous CIE documents from 1978 and the joint CIE-IAU (International Astronomical Union) publication of 1984 .

The other aspects of light obtrusion are covered in detail by another CIE technical committee, TC 5.12 "obtrusive light", which drew up a guide to evaluation of the environmental effects of light and recommendations for limit values which should not be exceeded in new installations; essentially these apply to undesirable effects on

- near neighbours

- road users

- astronomical observation

Light is analysed in terms of quantity, direction, and spectrum, for harmful effects in terms of "discomfort" or "reduction of visual capacity".

\section{Sky Glow}

Within the framework of this article, we will limit ourselves to the effects of functional public road luminaires and decorative urban luminaires on the luminous halo called "sky glow" in the night sky. But what are we talking about exactly? Sky glow corresponds to the extensive, diffuse band of light in the night sky which is visible over towns, airports and industrial and sport complexes. It results from radiation diffused by the constituents of the atmosphere (molecules, aerosols, pollutant particles).

We can distinguish:

- the natural glow due to radiation from celestial sources and the luminescence of the upper atmosphere, and

- the artificial halo due to:

1. direct radiation towards the sky from lamps and lights, and

2. radiation reflected by lighted surfaces.

The artificial glow depends not only to the design of the installations, but also on atmospheric conditions (humidity, clouds, haze, pollution).

To understand the effect of the diffuse sky glow, we must realise that any observation of a light-emitting object (either visual, photographic or electronic) 
amounts to an appreciation of the contrast $C$ between the luminance of the object and the luminance of the background against which the object is observed:

$$
C=\frac{L_{\text {object }}-L_{\text {background }}}{L_{\text {background }}}
$$

The overall stray light causes a light veil that extends over the field of observation. This veil has a luminance as well, that will be called $L_{v}$. The veiling luminance has to be added to all luminances in the field of observation. All contrasts will be reduced as follows:

$$
\begin{aligned}
C^{\prime} & =\frac{\left(L_{\text {object }}+L_{v}\right)-\left(L_{\text {background }}+L_{v}\right)}{L_{\text {background }}+L_{v}} \\
& =\frac{L_{\text {object }}-L_{\text {background }}}{L_{\text {background }}+L_{v}}
\end{aligned}
$$

$C^{\prime}$ is always $<C$.

When the luminance of the halo increases, the observed object can disappear from the field of vision, especially when we are dealing with a star which does not have a sharp image when seen through the instrument of observation. With the naked eye, the value of $L_{\text {object }}$ is very weak.

To limit the effect due to artificial glow, CIE committee TC 4.21 limits the percentage of a lamp's flux which can be directed above the horizontal plane passing through the light sources in their operating positions. The Upward Waste Light Ratio (UWLR) is the proportion of the flux of a luminaire that is emitted above the horizontal when the luminaire is mounted in its installed position.

$$
U W L R(\%)=\frac{U L O R(\%)}{U L O R \%+D L O R \%}=\frac{\% \text { lampflux } \nearrow}{\% \operatorname{lampflux} \nearrow+\% \operatorname{lampflux} \searrow}
$$

where the Upward Light Output Ratio (ULOR) is the proportion of the flux of the lamps of a luminaire that is emitted above the horizontal when the luminaire is mounted in its normal, designed position, and the Downward Light Output Ratio (DLOR) is the proportion of the flux of the lamps of a luminaire that is emitted below the horizontal.

The UWLR has limit values which differ according to the environment. The limits recommended are based on:

- the level of lighting existing in the zone

- the types of technologies available for the task to light

- the hours of operation

- the measurable and contractual photometric data 


\section{Zoning}

The concept of zoning has arisen from studies of the potential conflict between the photometric requirements for night-time activity, quality of life and the integrity of the environment. When a pollutant activity can not be completely suppressed, the harmful consequences are not identical for all the sites. Zoning does not stop pollution but it does constitute a frame of reference. Zoning must be complemented by specifying the distance in $\mathrm{km}$ between the zone limits and the point of reference (Tables 1, 2 and 3).

Table 1. Environmental Zones according to the CIE 126 Zoning System

\begin{tabular}{|c|c|}
\hline $\begin{array}{c}\text { Zone } \\
\text { rating }\end{array}$ & Description \\
\hline E1 & $\begin{array}{c}\text { Areas with intrinsically dark landscapes: National Parks, areas of } \\
\text { outstanding natural beauty (where roads usually are unlit) }\end{array}$ \\
\hline E2 & $\begin{array}{c}\text { Areas of "low district brightness": generally outer urban and rural } \\
\text { residential areas (where roads are lit to residential road standard) }\end{array}$ \\
\hline E3 & $\begin{array}{c}\text { Areas of "middle district brightness": generally urban residential } \\
\text { areas (where roads are lit to traffic route standard) }\end{array}$ \\
\hline E4 & $\begin{array}{c}\text { Areas of "high district brightness": generally urban areas having } \\
\text { mixed residential and commercial land use with high night-time } \\
\text { activity }\end{array}$ \\
\hline
\end{tabular}

Table 2. Recommendations for Limitation of Sky-Glow (CIE 126)

\begin{tabular}{|c|c|c|}
\hline Zone rating & UWLR (\%) & Astronomical activities \\
\hline E1 & 0 & Observatories of (inter)national standing \\
\hline E2 & $0-5$ & Postgraduate and academic studies \\
\hline E3 & $0-15$ & Undergraduate studies, amateur observations \\
\hline E4 & $0-25$ & Casual sky viewing \\
\hline
\end{tabular}

Table 3. Minimum Distance between Zone Borderlines and the Reference Point according to the CIE 126 System

\begin{tabular}{|c|c|c|c|}
\hline \multirow{2}{*}{$\begin{array}{c}\text { Zone rating of } \\
\text { reference point }\end{array}$} & \multicolumn{3}{|c|}{ Zone rating of surrounding zones } \\
& Distance (km) to borderline of surrounding zones \\
& E1-E2 & E2-E3 & E3-E4 \\
\hline E1 & 1 & 10 & 100 \\
\hline E2 & & 1 & 10 \\
\hline E3 & & & 1 \\
\hline E4 & \multicolumn{3}{|c|}{ No limits } \\
\hline
\end{tabular}




\section{Another Approach}

Knowledge of ULOR or UWLR of a light in its position of operation alone does not seem sufficient to us and certainly not sufficiently selective. To expand on this statement, we calculated distributions of light on a 1-km section of an actual road lit successively by 7 different models of functional luminaires and 3 different models of decorative luminaires (Figure 1).

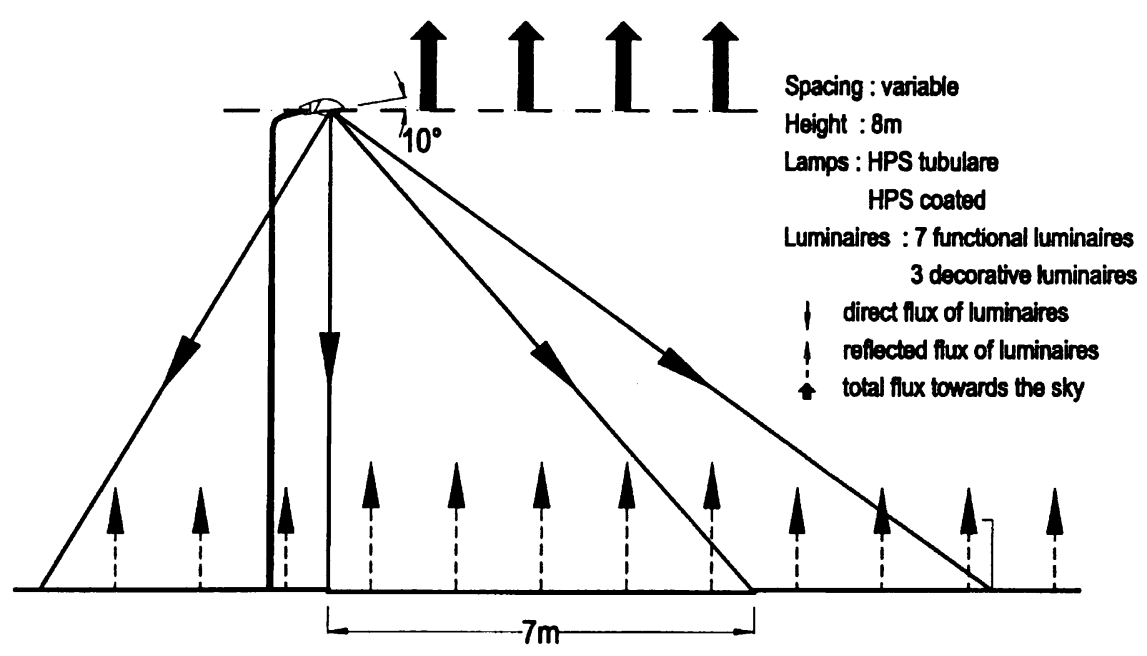

Figure 1. Upwards Emission of Light.

The functional luminaires are differentiated by their type of protector (flat, rounded, curved, deep, refracting (Figure 2) and by the choice of source (HPS, tubular or coated bulb). All the functional luminaires are inclined between $0^{\circ}-10^{\circ}$ in unilateral arrangement. Therefore the spacing and the flux of the luminaires was calculated so that in all cases, the road surface $(\mathrm{R} 3, \mathrm{Q} 0=0.07)$ was lit at the start of operation with an average luminance $L_{a v}$ of $1 \mathrm{~cd} / \mathrm{m}^{2}$, general uniformity $U g>60 \%$ and longitudinal uniformity $>70 \%$.

In Tables 4 to 7 we present for each case the calculated total flux per unit length (lumens $/ \mathrm{km}$ ) for (1) the lamps, (2) the light emitted directly upwards, and (3) the light reflected by the ground.

For the total flux $/ \mathrm{km}$ (lumens) reflected by the ground (3), we calculated separately:

1. the flux reflected by the road surface alone, with a coefficient of reflection of $18 \%$ in the case of asphalt ( $31 \%$ in the case of concrete);

2. the flux reflected by all of the ground except the road surface, with a coefficient of reflection of $5 \%$.

In Table 8 we compare for each case (1) UWLR, (2)total flux reflected by the lit surfaces, and (3) total flux lumens/km of lamps. 

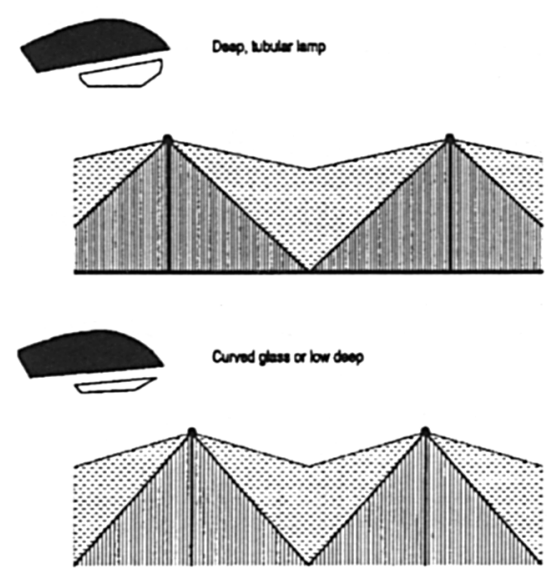
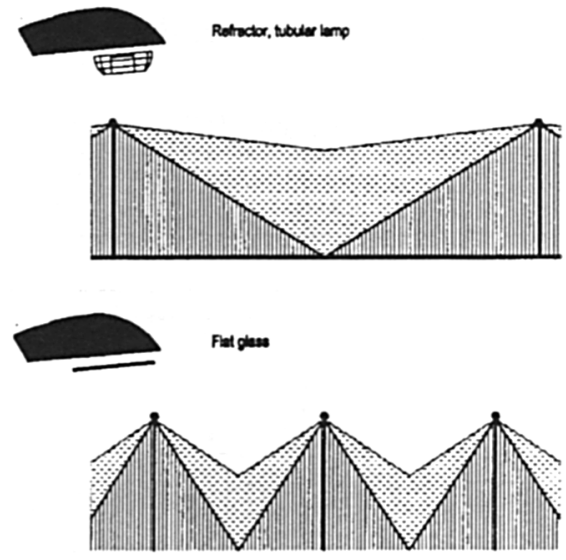

Figure 2. Light Distribution according to Type of Projector.

Table 4. Functional Road Lighting Luminaires: Lumens/km for $L_{a v}=1 \mathrm{~cd} / \mathrm{m}^{2}$

Tubular HPS lamps $\quad \mathrm{R} 3, \mathrm{Q} 0=0.07 \quad$ UI $>70 \%$

\begin{tabular}{|c|c|c|c|c|}
\hline Protector bowl & Lamps (1) & Direct (2) & Indirect (3) & Total \\
\hline Flat glass & 360000 & 0 & 30000 & 30000 \\
\hline Lowdeep glass & 294000 & $1200(0.4 \%)$ & 26000 & 27200 \\
\hline Curved glass & 294000 & 1200 & 27000 & 28200 \\
\hline Deep bowl & 270000 & $5000(1.8 \%)$ & 24000 & 29000 \\
\hline Refractor bowl & 220000 & 6200 & 19000 & 25200 \\
\hline Axial deep bowl & 200000 & 2000 & 19000 & 21000 \\
\hline & & 0 to $2.8 \%$ & $\pm 9 \%$ & $\pm 10 \%$ \\
\hline
\end{tabular}

Table 5. Functional Road Lighting Luminaires: Lumens/km for $L_{a v}=1 \mathrm{~cd} / \mathrm{m}^{2}$ - Influence of the Road Surface

Tubular HPS lamps $\mathrm{R} 1, \mathrm{Q} 0=0.10 \quad$ UI $>60 \%$

\begin{tabular}{|c|c|c|c|c|}
\hline Protector bowl & Lamps (1) & Direct (2) & Indirect (3) & Total \\
\hline Flat glass & 220000 & 0 & 29000 & 29000 \\
\hline Deep bowl & 195000 & 4000 & 22000 & 26000 \\
\hline Refractor bowl & 175000 & 5200 & 19000 & 24200 \\
\hline
\end{tabular}


Table 6. Functional Road Lighting Luminaires: Lumens/km for $L_{a v}=1 \mathrm{~cd} / \mathrm{m}^{2}$

Coated HPS lamps $\quad \mathrm{R} 3, \mathrm{Q} 0=0.07 \quad \mathrm{U}_{L}>70 \%$

\begin{tabular}{|c|c|c|c|c|}
\hline Protector bowl & Lamp (1) & Direct (2) & Indirect (3) & Total \\
\hline Clear deep & 420000 & 6300 & 29000 & 35300 \\
\hline
\end{tabular}

Table 7. Decorative Luminaires: Lumens $/ \mathrm{km}$ for $L_{a v}=1 \mathrm{~cd} / \mathrm{m}^{2}$

$\mathrm{R} 3, \mathrm{Q} 0=0.07 \quad \mathrm{UI}>70 \%$

\begin{tabular}{|c|c|c|c|c|c|}
\hline Lamp & Construction & Lamps (1) & Direct (2) & Indirect (3) & Total \\
\hline $\begin{array}{c}\text { Coated } \\
\text { HPS }\end{array}$ & Opal diffuser & 585000 & 234000 & 24500 & $\begin{array}{c}258000 \\
(50 \%)\end{array}$ \\
\hline $\begin{array}{c}\text { Compact } \\
\text { fluor. }\end{array}$ & $\begin{array}{c}\text { Clear protector } \\
\text { +reflector+roof }\end{array}$ & 430000 & 53000 & 25000 & 78000 \\
& & $(12 \%)$ & & $(18 \%)$ \\
\hline Ceramic & $\begin{array}{c}\text { Clear protector } \\
\text { +reflector+roof } \\
\text { Indirect light } \\
\text { source }\end{array}$ & 480000 & 9000 & 24000 & 33000 \\
& & $(1.8 \%)$ & & \\
\hline
\end{tabular}

Table 8. Reflected Flux (Lumens/km of R3/asphalt Road)

\begin{tabular}{|c|c|c|c|c|}
\hline For 1 cd/m ${ }^{2}$ & Zone & $\begin{array}{c}\text { UWLR (\%) } \\
(1)\end{array}$ & $\begin{array}{c}\text { Total lumens } \\
\text { reflected (2) }\end{array}$ & $\begin{array}{c}\text { Flux of lamps } \\
\text { (lumens) (3) }\end{array}$ \\
\hline Flat glass & E1? & 0.5 & 30000 & 360000 \\
\hline Low deep/curved glass & E1? & 0.5 & 27500 & 294000 \\
\hline Deep bowl (tubular lamp) & E2 & 2.9 & 29000 & 270000 \\
\hline Deep bowl (coated lamp) & E2 & 2.7 & 35300 & 420000 \\
\hline Refractor (tubular lamp) & E2 & 3.8 & 25200 & 220000 \\
\hline Axial deep bowl & E2 & 1.2 & 21300 & 201000 \\
\hline Opal diffuser & - & 45.7 & 258500 & 585000 \\
\hline Clear bowl reflector/roof & E4 & 16 & 78000 & 430000 \\
\hline $\begin{array}{c}\text { Clear bowl } \\
\text { reflector/roof/indirect }\end{array}$ & E2 & 3.1 & 33000 & 480000 \\
\hline
\end{tabular}


$\longrightarrow$ Flux reflected by the road
Flux reflected by the environment
Direct flux of luminaires towards sky

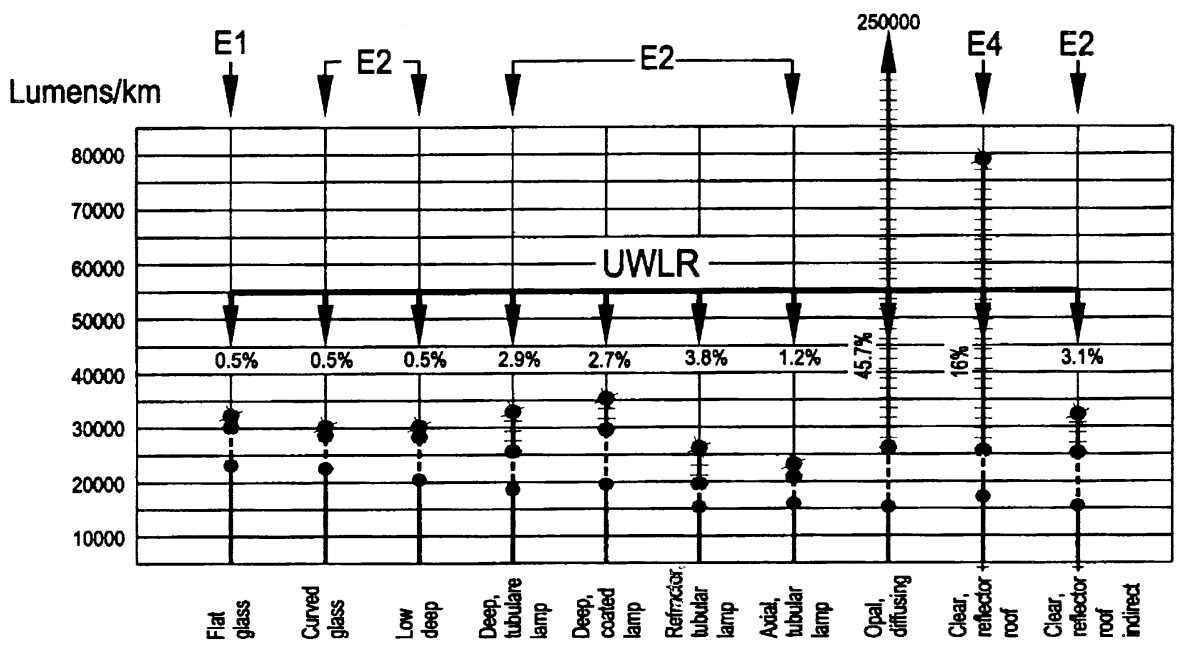

Figure 3. Upwards Emission of Light.

Figure 3 shows for each installation:

- the flux reflected by the road

- the flux reflected by the surrounding areas

- the flux emitted directly towards the sky by the lights

- the total value in lumens $/ \mathrm{km}$ of the pollutant flux

- the UWLR (\%) and the corresponding zone

\subsection{Findings for the Same Level of Performance with R3/Asphalt}

1. In tubular high pressure sodium lamps, the required flux $/ \mathrm{km}$ for the lamps can vary from 220000 lumens to 360000 lumens per $\mathrm{km}(+63 \%)$ according to the choice of bowls without the UWLR exceeding $3.8 \%$ (that is to say qualifying for zone E2, which requires $<5 \%$ ) (see Tables 4 to 6 and Figure 3).

2. With tubular high-pressure sodium lamps, the use of high-performance optics (flat glass, refractor, deep bowl) limits the flux $/ \mathrm{km}$ to lower values of both lamp flux and of the total flux reflected or emitted towards the sky (see Tables 4 to 6 ). 
3. The deep bowls associated with HPS diffused bulb lamps are the most pollutant in terms of reflected flux, although their UWLR (2.7\%) is satisfactory (see Figure 3).

4. The UWLR calculated from the ULOR measured in the laboratory for functional tubular HPS flat glass shows a minimum of $0.5 \%$, when the reality is $0 \%$. This is due to the "black flux" measured in the laboratory and to interference caused by reflections from the ground and the laboratory walls (Figure 3).

5. The direct flux emitted upwards by functional luminaires is very weak, of the order of $1 \%$ of the flux of the lamps, while the reflected flux is of the order of $9 \%$ (see Tables 4 to 6 ).

6. Tubular HPS axial luminaires have high-performance results in all fields, which shows that the maximum efficiency obtained by installation and optical performance results is perfectly compatible with minimum pollution (see Figure 3).

7. In decorative luminaires, the disastrous performance of total diffusers (i.e. spheres) is confirmed in all aspects (reflected flux and UWLR) (see Figure 3 ).

8. Decorative luminaires with optics and a non-visible lamp have an UWLR of $3.1 \%$ and thus can be used in zone E2. The total reflected flux is of the same order $( \pm 30000$ lumens $/ \mathrm{km}$ ) as the best functional luminaires. When the lamp is visible, these luminaires are compatible only with zone E4 (very urbanised) and within the limit of zone E3 (UWLR $=16 \%$ ) (see Figure 3).

\subsection{Findings for the Same Level of Performance with R1/Concrete}

Complementing the previous findings, we conclude that :

1. As the brightness of the road surface increases, the lighting designer needs less flux to obtain the same level of luminance. This decrease in installed flux will be compensated by an augmentation of the reflection coefficient of the road. Consequently, as a good first approximation, we can say that the total road-reflected flux will remain constant as the brightness of the road varies.

2. Nevertheless, as the brightness of the road surface increases, the lighting designer needs less flux to obtain the same level of luminance and consequently the direct-emitted flux will decrease.

3. On the whole, we can conclude that an increase in road-brightness will lead to a reduced value of the total upward-emitted flux.

\section{Conclusions}

1. Studying light pollution is more complex than simply evaluating the UWLR ratio. 
2. Not all refractors (European models in tubular HPS) are polluting since they can produce results among the best for minimum reflected flux in spite of an UWLR of $3.8 \%$ (see Figure 3 ).

3. The higher the performance of the luminaires within their recommended type of installation, the less light pollution there is.

4. The UWLR is admittedly indicative, but it is hardly selective and shows certain contradictions (Table 8). This is due to the fact that the direct flux upwards (ULOR) is very weak in general in relation to the direct flux downwards (DLOR).

5. The more the optics are hermetically sealed, the less need there will be for primary energy to install them and the less light there will be reflected towards the sky.

6. Lighting specialists need to take on board these new ideas about light pollution. Their resistance can be overcome by the most efficient and cheapest materials compatible with the performances currently proposed.

7. The idea that all kinds of light pollution are associated with the harmful efferts created by public and private lighting installations (glare from lights, signs, advertisements, and objects whose lighting has no collective advantage) could be a reason for conflict between astronomers and lighting specialists. In reality, however, in spite of appearances, both camps actually have the same views and objectives. If notice is taken of some of the astronomers' comments, it should be possible to develop very highperformance luminaires, at least for road lighting and urban functional lighting, that satisfy these stricter new criteria. 